\title{
Rainfall Forecasting Using Fourier Series
}

\author{
Nasser Rostam Afshar ${ }^{1}$ and Hedayat Fahmi ${ }^{2}$ \\ 1. Civil Engineering, Faculty of Engineering, University Malaysia Sarawak (UNIMAS), Kota Samarahan 94300, Malaysia \\ 2. Senior Research Office, Ministry of Energy, Tehran 1996832611, Iran
}

\begin{abstract}
The need for accurate rainfall prediction is readily apparent when considering many benefits in which such information would provide for river control, reservoir operation, forestry interests, flood mitigation, etc.. Due to importance of rainfall in many aspects, studies on rainfall forecast have been conducted since a few decades ago. Although many methods have been introduced, all the researches describe the study as complex because it involves numerous variables and still need to be improved. Nowadays, there are various traditional techniques and mathematical models available, yet, there are no result on which method provide the most reliable estimation. AR (auto-regressive), ARMA (auto-regressive moving average), ARIMA (auto-regressive integrated moving average) and ANNs (artificial neural networks) were introduced as a useful and efficient tool for modeling and forecasting. The conventional time series provide reasonable accuracy but suffer from the assumptions of stationary and linearity. The concept of neurons was introduced first which then developed to ANNs with back propagation training algorithm. Although certain ANNs) models are equivalent to time series model, but it is limited to short term forecasting. This Paper presents a mathematical approach for rainfall forecasting for Iran on monthly basic. The model is trained for monthly rainfall forecasting and tested to evaluate the performance of the model. The result shows reasonably good accuracy for monthly rainfall forecasting.
\end{abstract}

Keywords: Rainfall, forecasting, Fourier series, maximum, 1st year mean and minimum rainfall.

\section{Introduction}

Water resources project is for the control or use of water where utilization is proposed, the first question is usually how much water is needed. This is probably the most difficult of all the design problems to answer accurately because it involves social and economic aspects as well as engineering.

Almost all project designs depend on the answer to the question how much water can be expected. The answers to this question are found through the study of the occurrence and distribution of the natural waters. This study aims to forecast rainfall and correlate amount of precipitation to planning, design and use of limited water resources in the country.

In order to formulate rainfall, the forecaster must have reliable information such as current hydrologic conditions with the basin. He must know the amount and aerial distribution of rainfall and the water

\footnotetext{
Corresponding author: Nasser Rostam Afshar, PhD, research field: hydraulic structures. E-mail: anrostam@feng.unimas.my.
}

equivalent and aerial distribution of snow if present.

\section{Present Condition of the Country}

The geographical location of Iran is in such way that three different climatic conditions can be identified in its various regions [1]. The humid type is prevalent in the coastal area of the Caspian Sea with mean annual rainfall of $1000 \mathrm{~mm}$. The semi-arid type encountered in the mountainous regions of Zagross, with mean annual rainfall of $450 \mathrm{~mm}$ and, the arid type of the deserted expanses of the country with mean annual rainfall of 50 $\mathrm{mm}$.

Annual rainfall of the Caspian coast in northern Iran, has brought wet forests and woodlands and deserted regions of the country have a minimal annual precipitation.

The average annual rainfall in the country is about 250-300 mm. In the other word, mean annual rain fall of the country varies from $50 \mathrm{~mm}$. in Central, southern and South-eastern region to $1000 \mathrm{~mm}$ in western and northern regions [1]. 


\section{Mathematical Model}

Variations in precipitation from year to year make it important to design hydraulic structures like reservoirs. Over 100 different cycles in precipitation with periods up to $700 \mathrm{yr}$ in length have been reported by various investigators [2, 3]. No one has been successful, however, in employing cycles for forecasting precipitation several years in advance. The best evidence now available suggests that the occurrences of a series of wet or dry years is purely random and may be abnormal, but there is usually a tendency to return to the mean pattern. Hence, a period of abnormally heavy precipitation is sooner or later balanced by a dry period so that the mean over a long interval does not change appreciably.

Periodic-functions occur frequently in engineering problems. Their representation in terms of simple periodic functions, such as sins and cosine, is a matter of great practical importance, which leads to Fourier series [4]. These series are very powerful tool in connection with various problems involving ordinary and partial differential equations. To examine annual variation of precipitation, thus Fourier series, have been used as illustrated in Eq. (1).

$$
P(t)=A_{0}+\sum_{n=1}^{\infty} A_{n} \cos \frac{\pi n t}{T}+B_{n} \sin \frac{\pi n t}{T} \text { for } 0<t<2 T(1)
$$

The coefficients $A_{0}, A_{n}$ and $B_{n}$ can be estimated

$$
\begin{gathered}
A_{0}=\frac{1}{2 T} \int_{0}^{2 T} P(t) d t \\
A_{n}=\frac{1}{T} \int_{0}^{2 T} P(t) \cos \frac{\pi n t}{T} d t \\
B_{n}=\frac{1}{T} \int_{0}^{2 T} P(t) \sin \frac{\pi n t}{T} d t
\end{gathered}
$$
through the following relations:

Difference of observing and computed precipitation is analyzed as time series after harmonic simulation of rain gauge data. Variance analysis and Fisher test are done to examine homogeneity and static of time series.

Analysis indicates that the data selected belongs to a uniform statistical series which are random numbers. Forecasting precipitation, therefore, includes simulation of deterministic and stochastic variables [5]. Variables are simulated by producing random numbers.

\section{Analysis of Rainfall Data}

Table 1 shows 28 years average monthly Precipitation in the main basin of the country [6, 7].The results of simulation for 28 years from the model studies explained in section 3 and actual rainfall available from October to February are also tabulated in Table 1.

Table 2 indicates 28 years' precipitation along with simulation studies and actual precipitation for five and twelve months. Two scenery were proposed for analysis: actual rainfall may follow the trend of 28 years average rainfall, maximum rainfall, 1st year and mean precipitation obtained from the model studies (first scenery), and actual rainfall follows the pattern of minimum rainfall calculated from simulation (second scenery). From Table 2, it is clear that total actual rainfall from October to February is $75.6 \mathrm{~mm}$, which is

\begin{tabular}{|c|c|c|c|c|c|c|c|c|c|c|c|c|c|c|}
\hline & Month & Oct & Nov & Des & Jan & Feb & Mar & Apr & May & Jun & Jul & Aug & Sep & Total \\
\hline & 28-yearaverage & 7.9 & 19.0 & 34.17 & 39.8 & 43.0 & 40.5 & 34.3 & 22.7 & 6.2 & 2.8 & 3.3 & 4.6 & 258.3 \\
\hline & Percent & $3.1 \%$ & $7.4 \%$ & $13.24 \%$ & 15.4 & $16.7 \%$ & $15.7 \%$ & $13.3 \%$ & $8.8 \%$ & $2.4 \%$ & $1.1 \%$ & $1.3 \%$ & $1.8 \%$ & $100 \%$ \\
\hline \multirow{5}{*}{ 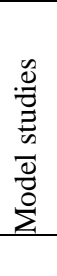 } & $\begin{array}{l}\text { Maximum } \\
\text { rainfall }\end{array}$ & 10.7 & 25.8 & 46.5 & 54.1 & 58.5 & 55.1 & 46.7 & 30.9 & 8.4 & 3.8 & 4.5 & 6.3 & 351.3 \\
\hline & 1st year rainfall & 13.6 & 24.5 & 28.5 & 30.8 & 29.0 & 24.6 & 16.3 & 4.4 & 2.0 & 2.0 & 2.4 & 3.3 & 184.9 \\
\hline & Mean rainfall & 8.1 & 19.4 & 35.0 & 40.7 & 44.0 & 41.4 & 35.1 & 23.2 & 6.3 & 2.9 & 3.4 & 4.7 & 264.3 \\
\hline & $\begin{array}{l}\text { Minimum } \\
\text { rainfall }\end{array}$ & 4.3 & 10.2 & 18.4 & 21.4 & 23.1 & 21.8 & 18.4 & 12.2 & 3.3 & 1.5 & 1.8 & 2.5 & 138.9 \\
\hline & Actual rainfall & 7.6 & 10.7 & 10.4 & 27.1 & 19.8 & & & & & & & & \\
\hline
\end{tabular}
approximately equal to minimum rainfall (subnormal) from model studies, i.e., $77.4 \mathrm{~mm}$ for the same duration.

Table 128 years average monthly precipitation( $\mathrm{mm})$, simulation of model studies for 28 years and Actual rainfall data. 
Table 228 years average precipitation, rainfall forecasted for 28 years and actual rainfall for 5 and 12 months.

\begin{tabular}{|c|c|c|c|c|c|}
\hline & \multirow{2}{*}{ Status } & \multicolumn{2}{|c|}{ Total } & \multicolumn{2}{|c|}{ Percentage } \\
\hline & & 5 months & 12 months & 5 months & 12months \\
\hline & 28 years average precipitation & 143.87 & 258.3 & $100 \%$ & $100 \%$ \\
\hline \multirow{5}{*}{ 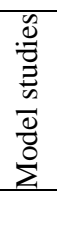 } & Maximum rainfall & 195.6 & 351.3 & 136.95 & 136.00 \\
\hline & 1st year rainfall & 126.4 & 184.9 & 87.50 & 71.61 \\
\hline & Mean rainfall & 147.2 & 264.3 & 102.31 & 102.31 \\
\hline & Minimum rainfall & 77.4 & 138.9 & 53.79 & 53.77 \\
\hline & Actual rain fall & 75.6 & - & 52.54 & - \\
\hline
\end{tabular}

Moreover, their variations with respect to 28 years average precipitation are 52.54 to 53.79 percent over five month.

Furthermore, if actual precipitation from March to September follows the trend of 28 years average rainfall, maximum rainfall, 1st year and mean rainfall obtained from model studies, thus, total actual rainfall from October to September equals to 190.03 (258.3143.87+75.6), 231.30, 134.10 and $192.70 \mathrm{~mm}$ respectively, which are less than 28 years average rainfall (258.30 mm).

Similarly, 28 years average precipitation, simulation of model studies for 300 years and actual rainfall from October to February are shown in Table 3. 28 years average precipitation along with simulation studies and actual precipitation for five and twelve months are also tabulated in Table 4.

It may be observed that (Table 4), minimum rainfall from model studies and actual rainfall from October to February are approximately equal and vary insignificantly from 43.44 to 52.54 percent of 28 years average precipitation for the same duration.

However, it may be, concluded that for the remaining month in the year, actual rainfall from March to September follows the trend of minimum rainfall forecasted from the model studies. Similarly, if precipitation from March to September follows the trend of 28 year average rainfall, maximum, 1st year and mean precipitation simulated, total actual rainfall from October to September equals to 190.03, 241.70, 157.20 and $189.90 \mathrm{~mm}$ which are less than 28 years average precipitation (258.30 $\mathrm{mm})$ too.

Furthermore, moving average for three, five and seven years along with annual and average rainfall from 1996 to 2011 have been shown in Table 5 and plotted in Fig. 1. This graph was used for evaluating the periods of dry or wet season. It may be observed that the dry period hold well from five to eight years approximately.

Table 328 years monthly precipitation $(\mathbf{m m})$, simulation of model studies for 300 years and Actual rainfall data.

\begin{tabular}{|c|c|c|c|c|c|c|c|c|c|c|c|c|c|c|}
\hline & Months & Oct. & Nov. & Dec. & Jan. & Feb. & Mar. & Apr. & May & Jun. & Jul. & Aug. & Sep. & Total \\
\hline & $\begin{array}{l}\text { 28-year } \\
\text { average }\end{array}$ & 7.9 & 19.0 & 34.17 & 39.8 & 43.0 & 40.5 & 34.3 & 22.7 & 6.2 & 2.8 & 3.3 & 4.6 & 258.3 \\
\hline & Percent & $3.1 \%$ & $7.4 \%$ & $13.24 \%$ & 15.4 & $16.7 \%$ & $15.7 \%$ & $13.3 \%$ & $8.8 \%$ & $2.4 \%$ & $1.1 \%$ & $1.3 \%$ & $1.8 \%$ & $100 \%$ \\
\hline \multirow{5}{*}{ 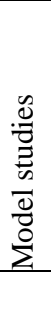 } & $\begin{array}{l}\text { Maximum } \\
\text { rainfall }\end{array}$ & 11.5 & 27.6 & 49.7 & 57.9 & 62.5 & 58.9 & 49.9 & 33 & 9 & 4.1 & 4.8 & 6.4 & 375.3 \\
\hline & $\begin{array}{ll}\text { 1st } & \text { year } \\
\text { rainfall } & \end{array}$ & 5.7 & 13.7 & 24.5 & 28.5 & 30.9 & 29 & 24.6 & 16.3 & 4.4 & 2 & 2.4 & 3.3 & 184.9 \\
\hline & Mean rainfall & 7.9 & 18.9 & 34.1 & 39.7 & 42.9 & 40.4 & 34.3 & 22.7 & 6.2 & 2.8 & 3.3 & 4.6 & 257.8 \\
\hline & $\begin{array}{l}\text { Minimum } \\
\text { rainfall }\end{array}$ & 3.5 & 8.3 & 14.8 & 17.2 & 18.7 & 17.6 & 14.9 & 9.9 & 2.7 & 1.2 & 1.5 & 2.0 & 112 \\
\hline & Actual rainfall & 7.6 & 10.7 & 10.4 & 27.1 & 19.8 & & & & & & & & \\
\hline
\end{tabular}


Table 428 years average precipitation, rainfall forecasted for 300 years and actual rainfall for five and twelve months.

\begin{tabular}{|c|c|c|c|c|c|}
\hline & \multirow{2}{*}{ Status } & \multicolumn{2}{|c|}{ Total } & \multicolumn{2}{|c|}{ Percentage } \\
\hline & & 5 months & 12 months & 5 months & 12 months \\
\hline & 28 years average precipitation & 143.87 & 258.3 & $100 \%$ & $100 \%$ \\
\hline \multirow{5}{*}{ 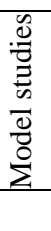 } & Maximum rainfall & 209.2 & 375.3 & 145.40 & 145.29 \\
\hline & 1st year rainfall & 103.30 & 184.9 & 71.80 & 71.58 \\
\hline & Mean rainfall & 143.50 & 257.8 & 99.74 & 99.80 \\
\hline & Minimum rainfall & 62.5 & 112 & 43.44 & 43.36 \\
\hline & Actual rainfall & 75.6 & - & 52.54 & - \\
\hline
\end{tabular}

Table 5 Moving 3, 5 and 7 years average, annual and average rainfall (mm).

\begin{tabular}{llllll}
\hline Year & 3 years & 5 years & 7 years & Annual & Average \\
\hline 1996 & 286.40 & 242.20 & 234.93 & 332.30 & 250 \\
1997 & 241.90 & 211.10 & 223.025 & 209.00 & 250 \\
1998 & 221.50 & 220.70 & 227.94 & 317.90 & 250 \\
1999 & 176.20 & 206.80 & 223.88 & 198.80 & 250 \\
2000 & 195.50 & 215.80 & 226.16 & 147.80 & 250 \\
2001 & 229.20 & 244.10 & 244.92 & 182.00 & 250 \\
2002 & 249.70 & 250.70 & 238.70 & 256.70 & 250 \\
2003 & 260.60 & 255.10 & 232.28 & 248.90 & 250 \\
2004 & 249.20 & 233.10 & 229.75 & 243.40 & 250 \\
2005 & 261.10 & 26.70 & 222.64 & 289.50 & 250 \\
2006 & 210.80 & 215.10 & & 214.80 & 250 \\
2007 & 209.80 & 210.8 & & 279.10 & 250 \\
2008 & 193.80 & & & 138.40 & 250 \\
2009 & 212.20 & & & 211.90 & 250 \\
2010 & & & 321.20 & 250 \\
2011 & & & & 193.70 & 250 \\
\hline
\end{tabular}

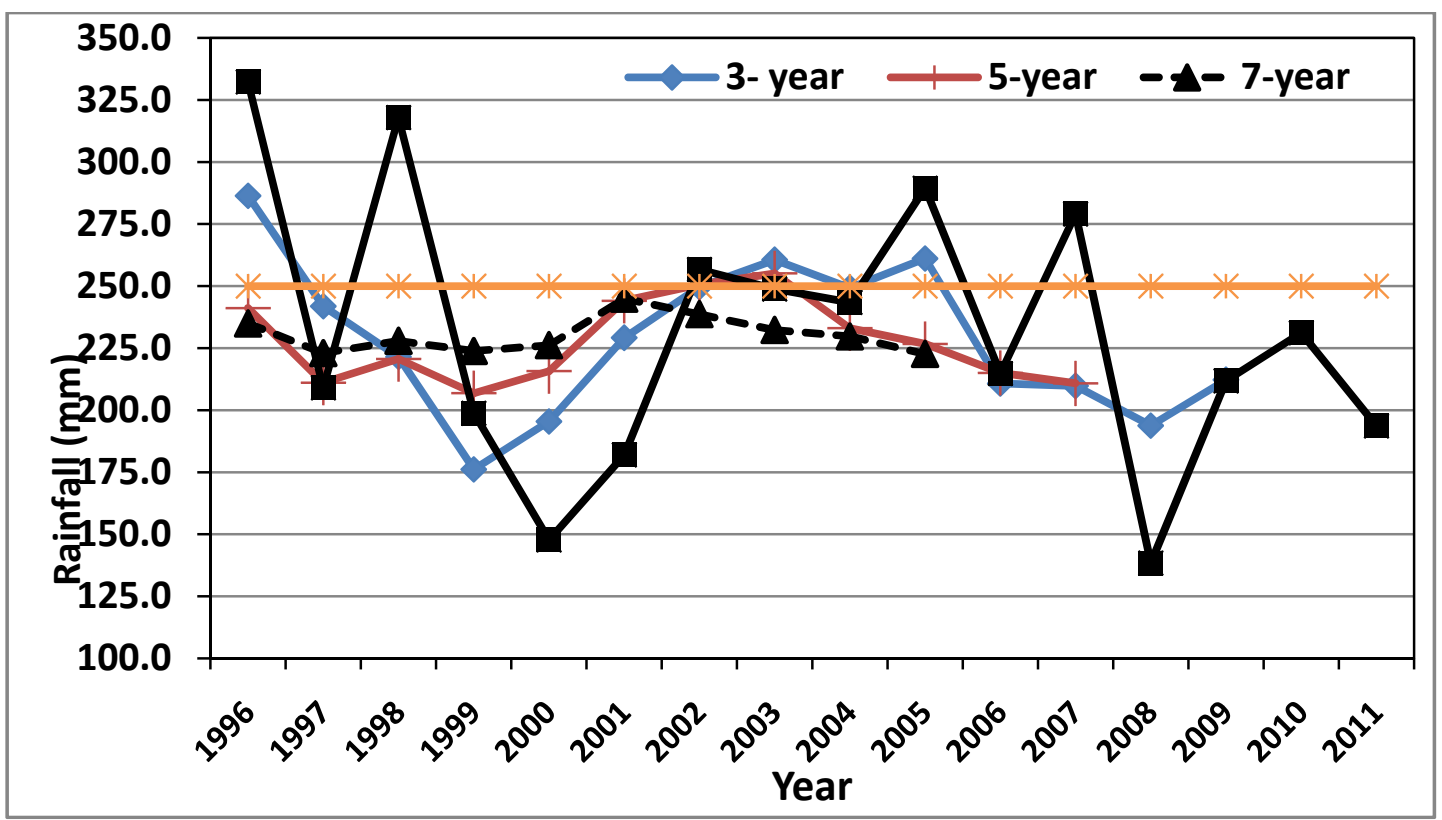

Fig. 1 Moving 3, 5 and 7 years average, annual and average rainfall. 


\section{Conclusions}

Analysis of rainfall data with 28 years in length along with simulation for 28 and 300 years, indicate the following:

(1) Annual rainfall of the country would follow the trend of Minimum rainfall obtained from model studies (dry period which may last from 5 to 8 years);

(2) Time distribution of annual rainfall has been shifted about one month;

(3) Analysis of data indicates snow melting process at least one month earlier. It may be due to climate change phenomena.

\section{Acknowledgments}

The authors wish to acknowledge the Faculty of Engineering University Malaysia Sarawak for their financial support, Head of the water engineering department, Water and Power University of
Technology Tehran, and Iran water management organization in collaboration in succeeding this article. Besides, technical guidance and advices throughout the study is highly appreciated.

\section{References}

[1] Meteorological Organization, Annual Report, Tehran, 1993-1994.

[2] R. K. linsley, Water Resources Engineering, international student edition, 1979.

[3] R. K. Linsley, Applied Hydrology, Me Graw: Hill Book Company, Inc., New York, 1983.

[4] E. Kreyszig, Advanced Engineering Mathematics, Mohinder Singh Sejwal for wily Eastern limited, Paris, 1985.

[5] V. Yevjevich, Probability and Statistics in Hydrology, Water Resources Publication, USA, 1992.

[6] Water Resources Organization, Rainfall Forecasting, Tehran, 1995.

[7] Water Resources Organization, Annual Report, Tehran, 1960-1995. 